\title{
In situ binding of islet hormones in the isolated perfused rat pancreas: evidence for local high concentrations of islet hormones via the islet-acinar axis
}

\author{
A. Nakagawa ${ }^{1}$, J. I. Stagner ${ }^{2}$, E.Samols ${ }^{1}$ \\ ${ }^{1}$ Department of Medicine, University of Louisville, Louisville, Kentucky, USA \\ ${ }^{2}$ Department of Veterans Affairs Medical Center, Louisville, Kentucky, USA
}

\begin{abstract}
Summary Insulin and somatostatin reportedly affect pancreatic acinar cell function via specific receptor binding. Theoretically peri-insular levels depend on the islet-acinar portal system, but the actual hormone levels have never been demonstrated. Rat pancreata were perfused anterogradely or retrogradely with ${ }^{125}$ I-insulin, -somatostatin, or -glucagon (each, $\cong 10^{-11} \mathrm{~mol} / \mathrm{l}$ ). Tracer binding was determined from differences between influx and efflux radioactivity. Saturable binding was observed for insulin and somatostatin, but not for glucagon. Binding in the absence of unlabelled peptides was significantly higher during retrograde perfusion than during anterograde perfusion for insulin $(25.9 \pm 2.6$ vs $16.0 \pm 2.1 \%$, mean $\pm \mathrm{SD}$; each, $n=4 ; p<0.001)$ and somatostatin $(18.4 \pm 2.0$ vs $13.6 \pm 1.2 \%$; each, $n=3 ; p<0.05)$. Non-specific binding was similar in both directions.
\end{abstract}

These findings are attributable to endogenous hormones acting as unlabelled ligands competing with the tracers during anterograde perfusion. This conclusion was supported by the demonstration that endogenous insulin stimulation by D-glucose, but not by L-glucose, caused a decrease in labelled insulin binding only during anterograde perfusion. Displacement curves obtained during retrograde perfusion showed that interstitial concentrations of insulin and somatostatin were $7.5 \times 10^{-9}$ and $1.1 \times 10^{-9} \mathrm{~mol} / \mathrm{l}$, respectively. Thus, the exocrine pancreas is indeed exposed to locally high concentrations of islet hormones. [Diabetologia (1995) 38: 262-268]

Key words Insulin, somatostatin, glucagon, islet-acinar portal system, exocrine pancreas.
It is well established that insulin has stimulating effects on pancreatic acinar cell function via its binding to specific receptors $[1,2]$. Other islet hormones, i.e., somatostatin (SS), glucagon, and pancreatic polypeptide, are reported to suppress exocrine pancreatic function, at least in vivo [2]. Among these three peptides only SS has been proven conclusively to have specific receptors on acinar cells [3-5]. Histological studies have demonstrated that efferent vessels from islets go through neighbouring exocrine tissue as a fenestrated vessel or connect with

Received: 6 June 1994 and in revised form: 5 August 1994

Corresponding author: Dr. A. Nakagawa, Department of Internal Medicine II, School of Medicine, Kanazawa University, 13-1 Takara-machi, Kanazawa 920, Japan

Abbreviations: SS, Somatostatin; TCA, trichloroacetic acid. surrounding acinar capillary beds (islet-acinar portal system) [6-8]. Therefore, it has been proposed that the effects of islet hormones on acinar cells could be mediated by locally high concentrations of the islet peptides through an islet-acinar portal system [1].

Although the microanatomy of the islet-acinar portal system provides an attractive model, neither definite physiological evidence for the model nor real exocrine interstitial hormone levels have been shown as yet. While an islet-acinar portal system has been demonstrated anatomically in various species, it is also widely accepted in most species that some portions of the acinar tissue receive their own distinct arterial blood supply [2]. In the rat, which has been the model in many prior reports concerning islet hormone effects on acinar cell function, only $6-10 \%$ of the total pancreactic blood supply 
goes to islets $[9,10]$. In this same species, efferent vessels from islets draining directly into collecting venules (i.e., into the systemic circulation) have been demonstrated $[6,8]$. It has been also reported that only small islets provide their effluent flow to the acinar tissue in the rat pancreas [6]. From these findings, Holst [2] concluded that the majority of acinar cells are exposed to systemic levels of circulating islet hormones and that locally high concentrations of islet hormones are not essential to the islet-acinar axis. Furthermore, as to fenestrated venous capillaries [6], it must be considered that the fenestrae are not open pores but are actually regulatory structures which may inhibit the passage of large molecules [11]. Thus, the role of locally delivered islet hormones in the islet-acinar axis is open to discussion.

We recently measured insulin and SS concentrations in dialysates obtained from the exocrine interstitial space in the isolated dog pancreas using a microdialysis technique [12]. This study demonstrated that retrograde perfusion reverses the direction of the islet-acinar portal system (i.e., islets $\rightarrow$ acini is reversed into acini $\rightarrow$ islets). In the present study, we measured the removal of radiolabelled islet hormones from perfusate and thus binding to receptors in the isolated rat pancreas perfused anterogradely vs retrogradely. During anterograde perfusion, endogenous islet hormones delivered to the exocrine interstitial space via the islet-acinar portal system may be regarded as unlabelled ligands competing with exogenously infused tracers. During retrograde perfusion, endogenous hormones are theoretically prevented from reaching the exocrine tissue, so that there should be no binding competition for acinar cell receptors (Fig. 1). By comparing anterograde tracer binding with the displacement curve obtained during retrograde perfusion, we were able to estimate interstitial islet hormone levels within the pancreas. This appears to be the first study demonstrating experimentally that acinar cells are exposed to high concentrations of islet hormones via directed vascular flow from islet to acini within the isolated perfused pancreas.

\section{Materials and methods}

Male Sprague-Dawley rats weighing 340-410 g, fed ad libitum, were anaesthetized with sodium pentobarbital injected intraperitoneally $(50 \mathrm{mg} / \mathrm{kg})$. Pancreatic isolation was performed by a method described elsewhere [13] with the modification of the total exclusion of the duodenum. For duodenal exclusion, all vessels between the duodenum and the pancreas were ligated and cut. The hepatic end of the common bile duct was cut, and through the open end of the duct, pancreatic juice was released to prevent stasis and oedema. The arterial catheter was placed in the abdominal aorta at the level of the left renal artery, and the venous catheter was inserted in the portal vein [13].
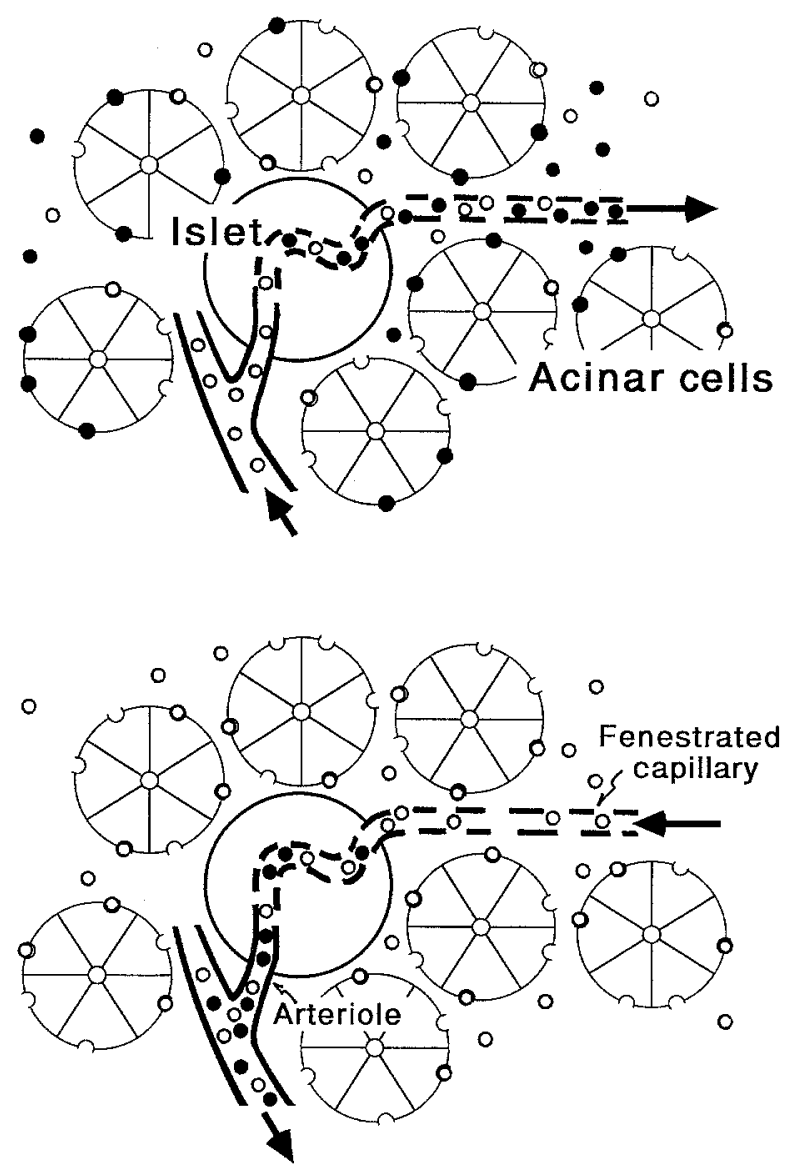

Fig. 1. Schematic principle of the present study. An islet hormone tracer $(0)$ is infused either anterogradely or retrogradely. During anterograde perfusion (upper), the endogenous islet hormone (•) is delivered to the exocrine interstitial space via an islet-acinar directed microcirculation (islet-acinar portal system), and could compete with the tracer for specific receptors on acinar cells. During retrograde perfusion (lower), endogenous islet hormones are prevented from reaching the exocrine tissue so that there might be no tracer binding competition by the endogenous peptide

The pancreas was placed in a chamber containing perfusion medium maintained at $37-38^{\circ} \mathrm{C}$, and was perfused in a non-recirculating system [13]. The perfusion medium was a modified Krebs-Ringer bicarbonate buffer containing $4 \%$ dextran (average mol. wt. 74,200), $0.2 \%$ bovine serum albumin (radioimmunoassay grade), and fumarate, pyruvate, and glutamate (each, $5 \mathrm{mmol} / \mathrm{l}$ ). The solution also contained $7 \mathrm{mmol} / \mathrm{l}$ glucose plus $3 \mathrm{mmol} / \mathrm{l}$ mixed amino acids [13] or $4 \mathrm{mmol} / 1$ glucose plus $1 \mathrm{mmol} / \mathrm{l}$ amino acids depending on the experiments. The medium was oxygenated with $95 \% \mathrm{O}_{2}-5 \% \mathrm{CO}_{2}$ and adjusted to $\mathrm{pH}$ 7.4. The perfusion rate was kept constant at $2.0 \mathrm{ml} / \mathrm{min}$ by a peristaltic pump. Retrograde perfusion was acheived by rapidly switching the influx and efflux tubing [14]. There were no significant differences in perfusion pressure between anterograde and retrograde perfusions $[13,14]$. The 70 -min experiments were started after an equilibrium period of approximately $20 \mathrm{~min}$. Efflux perfusate samples were collected at 1 min intervals throughout each experiment.

Radiolabelled islet hormone infusions. Human insulin (Peninsula Laboratories, Inc., Belmont, Calif,, USA) was radiolabelled with ${ }^{125} \mathrm{I}$ by a chloramine $\mathrm{T}$ method, and was purified 
A. Nakagawa et al.: Islet hormone binding in the perfused rat pancreas

by Sephadex G50 superfine column chromatography using $0.1 \mathrm{~mol} / 1$ acetate buffer with $0.1 \%$ bovine serum albumin (pH 3.8) as the eluting buffer. Specific activity was approximately $1,800 \mathrm{Ci} / \mathrm{mmol}$. HPLC-purified ${ }^{125} \mathrm{I}$-[Thr $\left.{ }^{11}\right]$ somatostatin-14 and ${ }^{125}$ I-glucagon 1-29 were purchased from Amersham UK (Amersham, Bucks., UK). Specific activities were approximately $2,000 \mathrm{Ci} / \mathrm{mmol}$, each. Unlabelled ligands, synthetic cyclic somatostatin-14 and glucagon 1-29, were obtained from Bachem Inc. (Torrance, Calif., USA).

For infusion, the radiolabelled peptides were diluted to prepare approximately $10^{-11} \mathrm{~mol} / 1$ solutions of each tracer $(3,500-4,000 \mathrm{cpm} / 100 \mu \mathrm{l})$ with or without various concentrations of the unlabelled peptide in $30 \mathrm{ml}$ of oxygenated perfusion medium. When the effects of endogenous insulin stimulation on insulin binding were studied, either $15 \mathrm{mmol} / 1$ of $\mathrm{L}$ - or D-glucose (Sigma Chemical Co., St. Louis, Mo., USA) was dissolved in the tracer solution. After being drawn into a disposable syringe, the tracer solution was placed in a water bath $\left(37-38^{\circ} \mathrm{C}\right)$ at least $15 \mathrm{~min}$ prior to infusion. Tracer infusion was conducted by rapid replacement of the perfusion circuit with a syringe injection pump infusing the tracer solution at a flow of $2.0 \mathrm{ml} / \mathrm{min}$. The original perfusion circuit was rapidly restored after $10 \mathrm{~min}$ of the tracer infusion. During the 70 -min perfusion, each pancreas received two separate tracer infusions of the same peptide $(\min 11-20$ and $\min 51-60$ ). Although combinations of the absence, presence, and graded concentrations of unlabelled peptide for tracer infusions performed in a single pancreas were chosen randomly, the infusions with lower concentrations of the cold ligand were generally conducted first.

To check the stability of radiolabelled peptides, aliquots of influx tracer solutions and efflux perfusate were precipitated with $20 \%$ trichloroacetic acid (TCA) solution and counted in a gamma spectrometer. In addition, tracer immunoreactivity with excess specific antibody before vs after perfusion was measured during several experiments.

Measurements. The radioactivity per unit volume in efflux perfusate and in influx tracer solution was measured in duplicate. Tracer binding was calculated as (influx cpm - efflux cpm)/ (influx cpm).

The perfusate samples obtained $10 \mathrm{~min}$ prior to tracer infusion were used to determine pre-infusion levels of islet hormones. In most cases perfusate samples obtained during tracer infusion were not assayed for cold hormones. When either Lor D-glucose was infused, cold insulin concentrations during tracer infusions were measured by adding an equal tracer level of radioactivity to the cold standard of the assay. Insulin concentrations were determined by double antibody radioimmunoassay with guinea-pig anti-rat insulin antibody and the rat insulin standard (both obtained from Linco Research, Inc., St. Louis, Mo., USA). The limit of detection of the assay was $18 \mathrm{pmol} / 1$. The coefficient of variation was 3-7\%. Radioimmunoassays for SS [12] and glucagon [15] have been described elsewhere. The limits of detection were $5 \mathrm{pmol} / \mathrm{l}$ and $30 \mathrm{ng} / 1$, and the coefficients of variation were $8-12 \%$ and $\cong 10 \%$, respectively.

\section{Data presentation and statistical analysis}

Results are presented as mean \pm SD. For statistical analysis in Figure 3 and Figure 5, two-way analysis of variance was performed, and thereafter Tukey's multicomparison method was utilized. Paired and unpaired Student's $t$-tests were also used as described in the text. The formulation of displacement curves of tracer binding was accomplished by approximations to log square-logit sigmoid curves using a least square method.
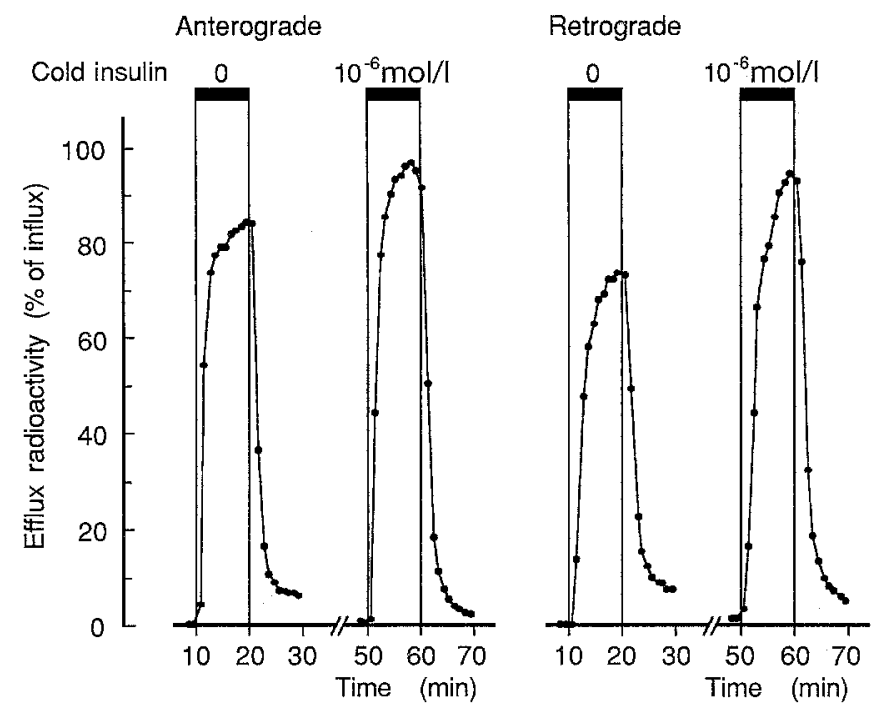

Fig. 2. Representative experiments of ${ }^{125} \mathrm{~T}$-insulin extraction by the isolated rat pancreas perfused anterogradely (left) and retrogradely (right). Pancreata were perfused with $7 \mathrm{mmol} / 1$ glucose $+3 \mathrm{mmol} / \mathrm{l}$ mixed amino acids. Approximately $10^{-11}$ $\mathrm{mol} / \mathrm{l}$ of ${ }^{125} \mathrm{I}$-insulin was infused with the presence or absence of $10^{-6} \mathrm{~mol} / 1$ cold (i.e., unlabelled) insulin

\section{Results}

TCA-precipitations before (influx) vs after passing through the pancreas (efflux) were $87.2 \pm 3.0$ vs $81.1 \pm 3.2 \%$, respectively for the insulin tracer ( $n=34$; the experimental number is based on a pool of all insulin tracer experiments where TCA-precipitations were measured; $p<0.001$, paired $t$-test), $73.1 \pm 2.2$ vs $57.2 \pm 2.9 \%$, respectively for the SS tracer $(n=18 ; p<0.001)$, and $81.0 \pm 2.3$ vs $60.3 \pm 1.9 \%$, respectively for the glucagon tracer $(n=6$; $p<0.001)$. Tracer immunoreactivity using excess antibodies in influx vs efflux perfusate was $77.5 \pm 4.9$ vs $70.1 \pm 3.8 \%$, for insulin $(n=16 ; p<0.001), 75.3 \pm 5.3$ vs $53.0 \pm 2.4 \%$ for SS $(n=10 ; p<0.001)$, and $79.0 \pm 4.6$ vs $55.5 \pm 2.4 \%$ for glucagon $(n=4$; $p<0.001)$. Conversely, there were no differences in tracer degradation between anterograde and retrograde perfusions ( $p>0.5-0.3$; unpaired $t$-test).

Representative experiments of insulin tracer extraction by the isolated rat pancreas are presented in Figure 2. Pancreata were perfused either anterogradely or retrogradely with $7 \mathrm{mmol} / \mathrm{l}$ glucose $+3 \mathrm{mmol} / 1$ mixed amino acids. The efflux perfusate radioactivity reached near steady state after $7 \mathrm{~min}$ of tracer infusion on both anterograde and retrograde perfusions, although retrograde perfusion showed a slightly slower early rise in efflux radioactivity. Therefore, tracer binding was calculated using the mean efflux radioactivity from 8-10 min after begining tracer infusion.

Radiolabelled tracer binding for insulin, SS, and glucagon was studied in the isolated rat pancreas 


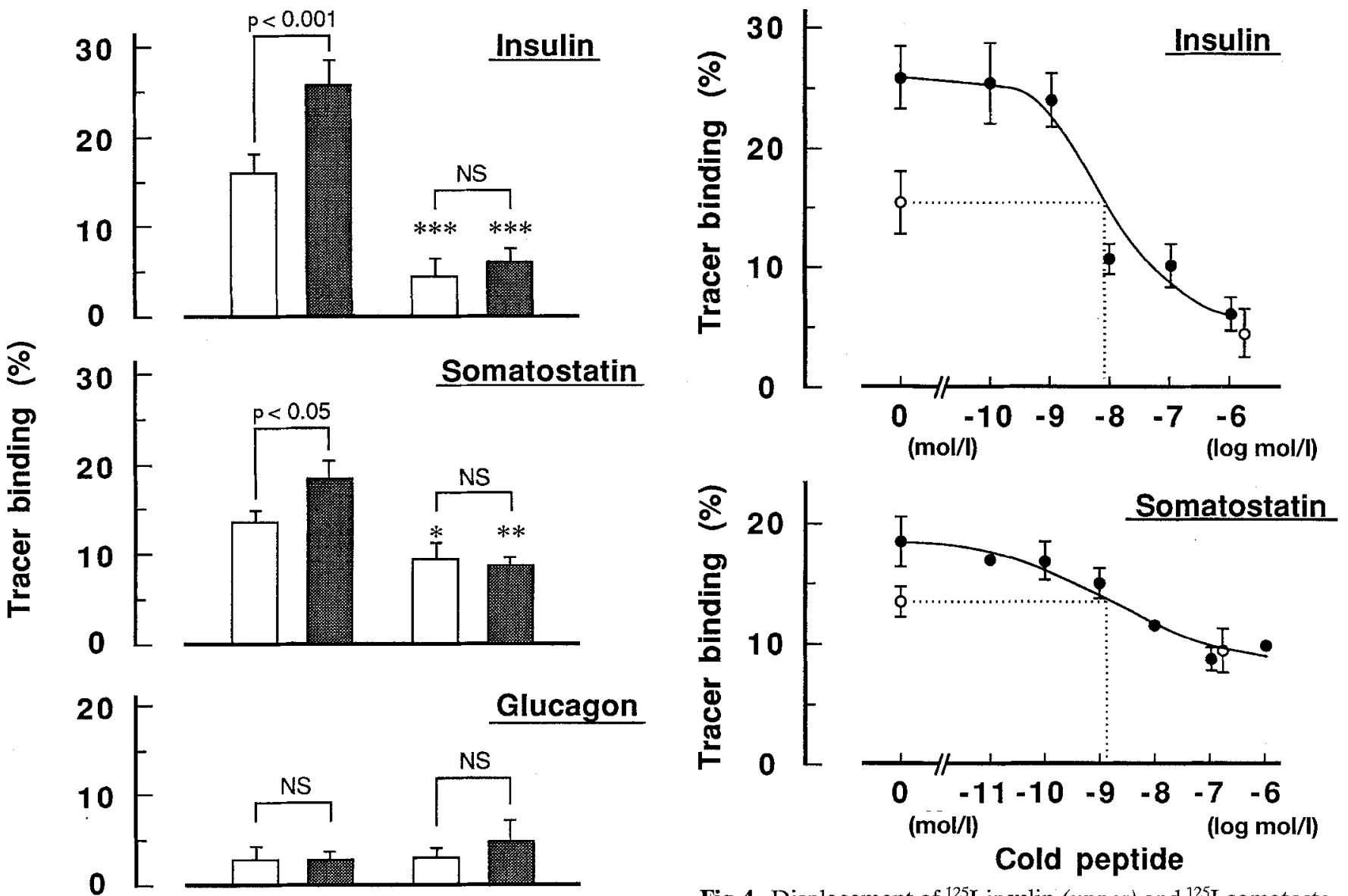

Fig. 4. Displacement of ${ }^{125}$ I-insulin (upper) and ${ }^{125}$ I-somatostatin (lower) binding in the isolated rat pancreas perfused retrogradely $(\bullet)$. For comparison, binding during anterograde perfusion is also shown $(0)$. Data are presented as mean \pm SD of three or four experiments (with vertical line), or as mean of two experiments (circle alone)

Fig.3. ${ }^{125} \mathrm{I}$-insulin (top), ${ }^{125} \mathrm{I}$-somatostatin (middle), and ${ }^{125} \mathrm{I}$ glucagon (bottom) binding in the isolated rat pancreas perfused anterogradely $(A)$ vs retrogradely $(R)$. Pancreata were perfused with $7 \mathrm{mmol} / 1$ glucose $+3 \mathrm{mmol} / 1$ amino acids (insulin and somatostatin), or with $4 \mathrm{mmol} / 1$ glucose $+1 \mathrm{mmol} / 1$ amino acids (glucagon). Radiolabelled peptides, each approximately $10^{-11} \mathrm{~mol} / 1$, were infused individually with the presence or absence of unlabelled (cold) peptides (insulin, $10^{-6}$ $\mathrm{mol} / \mathrm{l}$; somatostatin and glucagon, $10^{-7} \mathrm{~mol} / \mathrm{l}$ ). Data are presented as mean $\pm \mathrm{SD}$; insulin, each group, $n=4$; somatostatin and glucagon, each group, $n=3 ; * p<0.05 ; * * p<0.01$, *** $p<0.001$ vs without cold peptides

(Fig.3). Pancreata were perfused either anterogradely or retrogradely in the presence or absence of a large quantity of unlabelled relevant peptide (insulin, $10^{-6} \mathrm{~mol} / \mathrm{l}$, each group, $n=4$; SS and glucagon, $10^{-7} \mathrm{~mol} / \mathrm{l}$, each group, $n=3$ ) with $7 \mathrm{mmol} / 1 \mathrm{glu}$ cose $+3 \mathrm{mmol} / \mathrm{l}$ amino acids (insulin and SS) or $4 \mathrm{mmol} / \mathrm{l}$ glucose $+1 \mathrm{mmol} / 1$ amino acids (glucagon). There were no significant differences in pre-infusion levels of each endogenous islet hormone between anterograde and retrograde perfusions (anterograde vs retrograde concentrations were $1.67 \pm 0.91$ vs $1.78 \pm 0.61 \mathrm{nmol} / 1$ for insulin, $27 \pm 9.2$ vs $24 \pm 6.7 \mathrm{pmol} / \mathrm{l}$ for $\mathrm{SS}$, and $144 \pm 31$ vs $159 \pm 39 \mathrm{ng} / 1$ for glucagon).

Saturable tracer binding capacity was detected in the pancreas for insulin and SS (Fig. 3). Specific binding in the absence of unlabelled peptides was significantly higher on retrograde perfusion than on anterograde perfusion, whereas non-specific binding in the presence of excess unlabelled peptides was similar in either direction of perfusion. This difference could be attributable to endogenous islet hormones acting as unlabelled ligands competing with the tracers during anterograde perfusion. No specific binding was observed for glucagon. To assess the receptor binding capacity of the glucagon tracer, a liver perfusion was conducted (flow, $6 \mathrm{ml} / \mathrm{min}$ ); glucagon tracer extraction by the perfused rat liver in the absence or presence of $10^{-7} \mathrm{~mol} / \mathrm{l}$ unlabelled glucagon was 14.0 and $1.4 \%$, respectively.

Displacement curves of insulin and SS tracer binding in the isolated pancreas by unlabelled peptides were obtained during retrograde perfusion (Fig.4). Anterograde binding for insulin and SS in the absence of unlabelled peptides corresponded to retrograde binding in the presence of $7.5 \times 10^{-9} \mathrm{~mol} / 1 \mathrm{in}$ sulin $\left(95 \%\right.$ confidence limits $3.0 \times 10^{-9}-1.9 \times 10^{-8}$ 


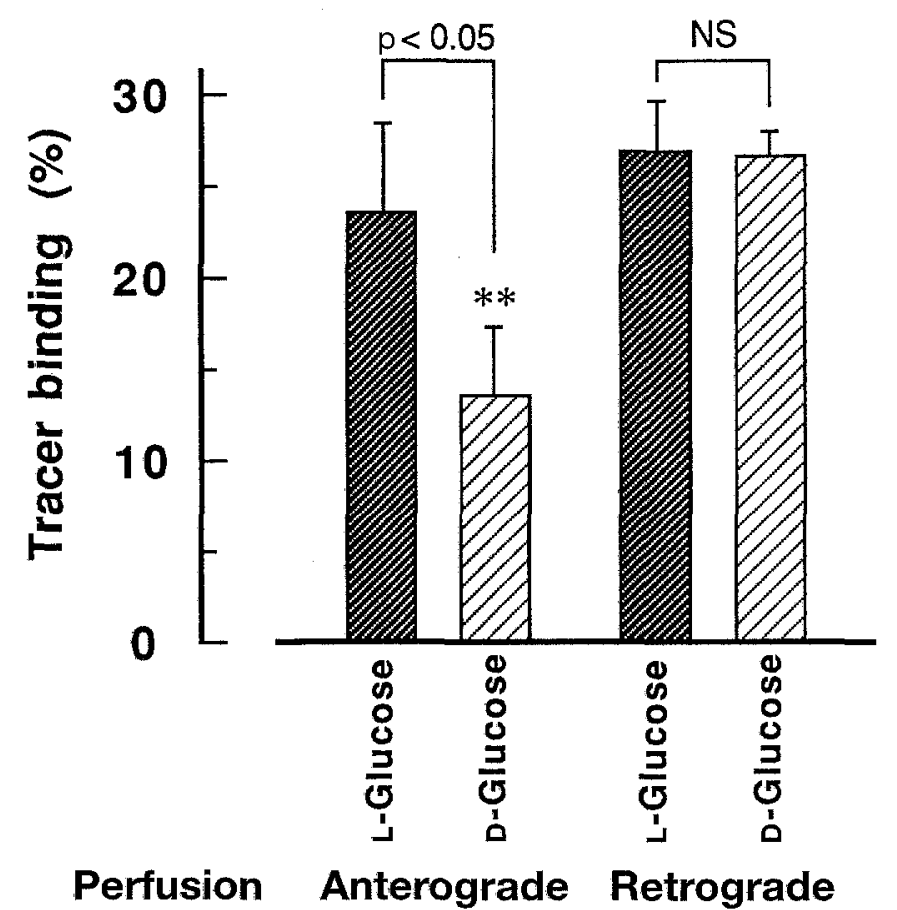

Fig.5. Effects of $\mathbf{L}$ - and D-glucose on ${ }^{125} \mathrm{I}$-insulin binding in the isolated rat pancreas perfused anterogradely and retrogradely. Pancreata were perfused with $4 \mathrm{mmol} / \mathrm{l}$ (D-)glucose $+1 \mathrm{mmol} /$ 1 amino acids. Approximately $10^{-11} \mathrm{~mol} / \mathrm{l}^{125} \mathrm{I}$-insulin was infused with either $15 \mathrm{mmol} / \mathrm{l} \mathrm{L}$-glucose or additional $15 \mathrm{mmol} / \mathrm{l}$ D-glucose. Mean $\pm \mathrm{SD}$; each group, $n=3$; ** $p<0.01$ vs retrograde perfusion

$\mathrm{mol} / \mathrm{l})$ and $1.1 \times 10^{-9} \mathrm{~mol} / \mathrm{l} \mathrm{SS}(95 \%$ confidence limits $\left.4.9 \times 10^{-11}-2.8 \times 10^{-8} \mathrm{~mol} / \mathrm{l}\right)$ on the displacement curves.

To confirm that the lower tracer binding on anterograde perfusion might be attributed to the presence of endogenous islet hormones, the effects of endogenous insulin stimulation on insulin binding were examined (Fig.5). Pancreata were perfused either anterogradely or retrogradely with $4 \mathrm{mmol} / 1$ (D-)glucose $+1 \mathrm{mmol} / 1$ mixed amino acids. Insulin tracer was infused together with either $15 \mathrm{mmol} / \mathrm{l}$ of biologically inactive L-glucose or $15 \mathrm{mmol} / \mathrm{l}$ of biologically active D-glucose (each group, $n=3$ ). Endogenous insulin concentrations during $\mathrm{L}-$ and D-glucose infusions were $0.22 \pm 0.11$ and $5.69 \pm 1.61 \mathrm{nmol} / 1$, respectively. On anterograde perfusion, insulin tracer binding during $\mathrm{D}$-glucose infusion was significantly smaller than that during L-glucose infusion, while there was no significant difference in tracer binding during L- and D-glucose infusions on retrograde perfusion. Comparing tracer binding during anterograde $\mathrm{L}$ - and D-glucose infusions with the retrograde displacement curve (Fig.4), interstitial insulin concentrations were estimated as $6.6 \times 10^{-10} \mathrm{~mol} / 1 \mathrm{dur}$ ing L-glucose infusion and $1.5 \times 10^{-8} \mathrm{~mol} / \mathrm{l}$ during $\mathrm{D}^{-}$ glucose infusion.

\section{Discussion}

The presence of insulin receptors on pancreatic acinar cells has been well documented [16-19]. SS receptors have also been shown on acinar cells [3-5]. To our knowledge, glucagon receptors have not been reported to occur on acinar cells. The present study, by measuring radiolabelled tracer recovery in perfusate from the isolated perfused pancreas, has demonstrated saturable binding for insulin and SS, but not for glucagon, in the pancreas. Since the isolated pancreas preparation contains both endocrine islets and exocrine acini, and islet cells reportedly have receptors for islet hormones [20], this saturable binding may not necessarily be entirely due to acinar cell receptors. However, autoradiographic studies showed markedly less binding of insulin [16, 19] and SS [5] in islets than in the exocrine tissue. The total volume of islets is reportedly less than $1 \%$ of the whole pancreatic volume [10]. Therefore, the participation of islets in the tracer binding may be regarded as practically negligible.

Considerable extraction of $50-80 \%$ of unlabelled SS by the in vivo dog pancreas [21] and the isolated perfused dog pancreas [22] has been reported. Taborsky and Ensinck [21] reported that glucagon did not show such a large degree of extraction, and Kawai et al. [22] reported that both glucagon and insulin were extracted to a lesser degree than SS. However, since these islet hormone extractions were determined by radioimmunoassays, the extraction could be the result of hormone degradation as well as receptor binding. Degradation of insulin by acinar cell membranes, not mediated by the receptor binding process, has been reported in the mouse [23]. Therefore, it is possible that SS and glucagon may also be degraded by acinar cells, enzymes present in blood, or other degradative factors which may present in perfusion fluid. TCA precipitability and immunoreactivity of each tracer decreased significantly after a single passage through the pancreas in the present study. It is interesting to note that insulin showed significant saturable binding with relatively little degradation, and glucagon showed no significant binding but great degradation, while SS showed both significant binding and a large degree of degradation.

The present study has demonstrated significantly higher binding of insulin and SS during retrograde perfusion than during anterograde perfusion. This phenomenon cannot be considered an artifact caused by retrograde perfusion because there was no significant difference in non-specific binding between anterograde and retrograde perfusions. We suggest that endogenous islet hormones compete with the infused radioactive tracer peptides for acinar cell receptors during anterograde perfusion, whereas endogenous hormones cannot reach the exocrine tissue during retrograde perfusion. This hypo- 
thesis was supported by demonstrating that changes in endogenous insulin levels produced alterations in insulin binding only during anterograde perfusion. The possibility that the endogenous SS may influence tracer binding in the pancreas has been suggested in a study by Garry et al. [5], but the authors did not consider that tracer binding was a potential means of measuring interstitial islet hormone concentrations.

Displacement curves for insulin and SS tracers were obtained during retrograde perfusion. If retrograde perfusion prevents endogenous islet hormones from reaching the exocrine tissue and removes endogenous islet hormones from the exocrine tissue, then these retrograde displacement curves may indicate the true tracer binding capacity of the whole pancreas (mainly composed of the exocrine tissue) without interference by endogenous hormones. Comparing anterograde tracer binding with the retrograde displacement curve therefore provides an estimate of exocrine interstitial concentrations of islet hormones. The estimated interstitial concentrations were $7.5 \times 10^{-9} \mathrm{~mol} / 1$ for insulin and $1.1 \times 10^{-9} \mathrm{~mol} / 1$ for SS. In comparison, rat peripheral insulin levels are reported to be in the range of $10^{-10} \mathrm{~mol} / \mathrm{l}$. These estimated interstitial concentrations corresponded to an approximately 4-4.5 fold increase in insulin and 40-45 fold increase in SS over efflux perfusate peptide concentrations. Since both hormones should be conveyed from islets to the acinar tissue by the same circulation, the discrepancy in the interstitial/perfusate concentration ratios of insulin vs SS is noteworthy, but cannot be explained at present.

The interstitial/perfusate concentration ratios for insulin during L-and D-glucose infusions (i.e., hypoand hyperglycaemic states) were 3.0 and 2.6 , respectively. Although the potential influence of osmolarity on tracer binding cannot be excluded, these ratios are relatively similar to the ratio obtained in the euglycaemic state (4.0-4.5). It has been reported that hyperglycaemia increased the absolute and fraction$\mathrm{al}$ (to the whole pancreas) islet blood flow in the in vivo rat pancreas [9]. It is uncertain, however, whether a fractional increase of islet flow occurs in the isolated pancreas, or whether the fractional islet flow increases can be detected by our interstitial/perfusate concentration ratios.

It must be recognized that all the acinar tissue may not be exposed to our estimated interstitial concentrations of islet hormones. It is believed that some portions of the acinar tissue which may have their own distinct arterial blood supply (non-islet-acinar portal area) may be exposed to peripheral levels of islet hormones, whereas islet-acinar portal areas receive islet efflux with considerably higher concentrations of the hormones (see Introduction). Our estimated interstitial concentrations are based on the binding capacity of the whole pancreas which contains both islet-aci- nar portal and non-portal areas. Theoretically, if only $6-10 \%$ of the total blood flow goes directly to the islets of the rat $[9,10]$, the portal area, if it were truly a separate compartment, should receive the same 6$10 \%$ of blood flow. However, applying our insulin binding data to a simple two-compartment model, the exocrine portal areas should receive more than $38 \%$ of the total pancreatic blood supply. A two-compartment model would completely separate islet-acinar portal area $(\mathrm{Cp}$, interstitial islet hormone level in the area; Fp, fractional flow of the area to the whole pancreas) and non-portal area ( $\mathrm{Cn}=0$, in the non-recirculating perfused pancreas; $\mathrm{Fn}=1-\mathrm{Fp}$ ). Suppose tracer binding corresponding to the interstitial hormone levels $(\mathrm{Cp}$ and $\mathrm{Cn})$ to be $\mathrm{B}(\mathrm{Cp})$ and $\mathrm{B}(\mathrm{Cn})=\mathrm{B}(0)$, respectively. Since tracer binding of the anterogradely perfused whole pancreas (B) should be a proportional average of $B(C p)$ and $B(C n)$, the equation of $\mathrm{FpB}(\mathrm{Cp})+\mathrm{FnB}(\mathrm{Cn})=\mathrm{B}$, then $\mathrm{FpB}(\mathrm{Cp})+(1-$ $F p) B(0)=B$ is given. Using data from our insulin tracer binding studies, i.e., $\mathrm{B}(0)=0.26, \mathrm{~B}=0.16$ and $0<\mathrm{B}(\mathrm{Cp})<\mathrm{B}$, Fp should be more than 0.38 . This implies either that there is a mixing of portal and systemic circulations or/and that islet hormone receptors are not expressed to the same degree in portal and nonportal exocrine areas. Bendayan and Grégoire [24] reported that, in streptozotocin-induced diabetic rats, acinar cells located in peri-insular regions (close to islets, presumably islet-acinar portal areas) were totally devoid of amylase, while both amylase-positive and negative cells were found in tele-insular regions (at a distance from islet, presumably non-portal areas). This phenomenon may be attributable to the difference in insulin receptor expression of acinar cells.

In conclusion, using tracer binding in the isolated rat pancreas perfused anterogradely vs retrogradely, we have demonstrated that (some portions of) exocrine acinar cells are indeed exposed to high concentrations of local islet hormones within the pancreas. Thus, it is reasonable to conclude that acinar cells adjacent to islets may be regulated by the presence of high concentrations of islet hormones in the interstitial fluid.

Acknowledgements. This work was supported by the Department of Veterans Affairs and the Diabetes Research and Education Foundation.

\section{References}

1. Williams JA, Goldfine ID (1985) The insulin-pancreatic acinar axis. Diabetes 34: 980-986

2. Holst JJ (1987) Does the endocrine secretion of the pancreas exert a local control of the exocrine secretion? Pancreas 2: 613-619

3. Esteve JP, Susini C, Vaysse N et al. (1984) Binding of somatostatin to pancreatic acinar cells. Am J Physiol 247: G62G69

4. Sakamoto C, Goldfine ID, Williams JA (1984) The somatostatin receptor on isolated pancreatic acinar cell plasma 
membranes. Identification of subunit structure and direct regulation by cholecystokinin. J Biol Chem 259: 9623-9627

5. Garry DJ, Garry MG, Williams JA, Mahoney WC, Sorenson RL (1989) Effects of islet hormones on amylase secretion and localization of somatostatin binding sites. Am J Physiol 256: G897-G904

6. Bonner-Weir S, Orci L (1982) New perspectives on the microvasculature of the islets of Langerhans in the rat. Diabetes 31: $883-889$

7. Henderson JR, Daniel PM (1979) A comparative study of the portal vessels connecting the endocrine and exocrine pancreas with a discussion of some functional implications. Q J Exp Physiol 64: 267-275

8. Ohtani O, Ushiki T, Kanazawa H, Fujita T (1986) Microcirculation of the pancreas in the rat and rabbit with special reference to the insulo-acinar portal system and emissary vein of the islet. Arch Histol Jpn 49: 45-60

9. Jansson L. Hellerström C (1983) Stimulation by glucose of the blood flow to the pancreatic islets of the rat. Diabetologia $25: 45-50$

10. Lifson N, Lassa CV, Dixit PK (1985) Relation between blood flow and morphology in islet organ of rat pancreas. Am J Physiol 249: E43-E48

11. Rippe B, Haraldsson B (1994) Transport of macromolecules across microvascular walls: the two-pore theory. Physiol Rev 74: 163-219

12. Nakagawa A, Samols E, Stagner JI (1993) Exocrine interstitial insulin and somatostatin in the perfused dog pancreas. Am J Physiol 264: G728-G734

13. Nakagawa A, Stagner JI, Samols E (1993) Suppressive role of the islet-acinar axis in the perfused rat pancreas. Gastroenterology 105: 868-875

14. Samols E, Stagner JI, Ewart RBL, Marks V (1988) The order of islet microvascular cellular perfusion is $\mathrm{B} \rightarrow \mathrm{A} \rightarrow \mathrm{D}$ in the perfused rat pancreas. J Clin Invest 82: 350-353
15. Samols E, Weir GC (1979) Adrenergic modulation of pancreatic $\mathrm{A}, \mathrm{B}$, and $\mathrm{D}$ cells. $\alpha$-Adrenergic suppression and $\beta$ adrenergic stimulation of somatostatin secretion, $\alpha$-adrenergic stimulation of glucagon secretion in the perfused dog pancreas. J Clin Invest 63: 230-238

16. Bergeron JJM, Rachubinski R, Searle N et al. (1980) Radioautographic visualization of in vivo insulin binding to the exocrine pancreas. Endocrinology 107: 1069-1080

17. Sankaran H, Iwamoto $Y$, Korc M, Williams JA, Goldfine ID (1981) Insulin action in pancreatic acini from streptozotocin-treated rats. II. Binding of ${ }^{125} \mathrm{I}$-insulin to receptors. Am J Physiol 240: G63-G68

18. Goldfine ID, Kriz BM, Wong KY, Hradek G, Jones AL, Williams JA (1981) Insulin action in pancreatic acini from streptozotocin-treated rats. III. Electron microscope autoradiography of ${ }^{125} \mathrm{I}$-insulin. Am J Physiol 240: G69-G75

19. Sakamoto C, Williams JA, Roach E, Goldfine ID (1984) In vivo localization of insulin binding to cells of the rat pancreas. Proc Soc Exp Biol Med 175: 497-502

20. Patel YC, Amherdt M, Orci L (1982) Quantitative electron microscopic autoradiography of insulin, glucagon, and somatostatin binding sites on islets. Science 217: 1155-1156

21. Taborsky GJ Jr., Ensinck JW (1983) Extraction of somatostatin by the pancreas. Endocrinology 112: 303-307

22. Kawai K, Orci L, Unger RH (1982) High somatostatin uptake by the isolated perfused dog pancreas consistent with an "insulo-acinar" axis. Endocrinology 110: 660-662

23. Goldfine ID, Williams JA, Bailey AC (1984) Degradation of insulin by isolated mouse pancreatic acini. Evidence for cell surface protease activity. Diabetes 33: 64-72

24. Bendayan M, Grégoire S (1987) Immunohisto- and cytochemical studies of pancreatic enzymes in peri-insular and tele-insular acinar cells of streptozotocin-induced diabetic rats. Pancreas 2: 272-282 